Review

\title{
CPT-cGMP Is A New Ligand of Epithelial Sodium Channels
}

\author{
Hong-Long Ji ${ }^{\bowtie}$, Hong-Guang Nie², Yongchang Chang³, Qizhou Lian ${ }^{4}$, Shan-Lu Liu ${ }^{5}$ \\ 1. Department of Cellular and Molecular Biology, University of Texas Health Science Center at Tyler, Tyler, Texas 75708, USA. \\ 2. Institute of Metabolic Disease Research and Drug Development, China Medical University, Shenyang 110001, China. \\ 3. Barrow Neurological Institute, St Joseph's Hospital and Medical Center, Phoenix, Arizona, 85013, USA. \\ 4. Department of Medicine, Li Ka Shing Faculty of Medicine, The University of Hong Kong, Hong Kong, China. \\ 5. Department of Molecular Microbiology and Immunology, Bond Life Sciences Center, University of Missouri, Columbia, MO 65211, USA.
}

$\square$ Corresponding author: Hong-Long (James) Ji, 11937 US Highway 271, 604 BMR, Tyler, TX 75708-3154. E-mail: james.j@uthct.edu. Telephone: 903-877-7418. Fax: 903-877-5438

() Ivyspring International Publisher. Reproduction is permitted for personal, noncommercial use, provided that the article is in whole, unmodified, and properly cited. See http://ivyspring.com/terms for terms and conditions.

Received: 2015.09.05; Accepted: 2015.11.11; Published: 2016.01.28

\begin{abstract}
Epithelial sodium channels $(\mathrm{ENaC})$ are localized at the apical membrane of the epithelium, and are responsible for salt and fluid reabsorption. Renal $\mathrm{ENaC}$ takes up salt, thereby controlling salt content in serum. Loss-of-function ENaC mutations lead to low blood pressure due to salt-wasting, while gain-of-function mutations cause impaired sodium excretion and subsequent hypertension as well as hypokalemia. ENaC activity is regulated by intracellular and extracellular signals, including hormones, neurotransmitters, protein kinases, and small compounds. Cyclic nucleotides are broadly involved in stimulating protein kinase $A$ and protein kinase $G$ signaling pathways, and, surprisingly, also appear to have a role in regulating ENaC. Increasing evidence suggests that the cGMP analog, CPT-cGMP, activates $\alpha \beta \gamma-E N a C$ activity reversibly through an extracellular pathway in a dose-dependent manner. Furthermore, the parachlorophenylthio moiety and ribose 2'-hydroxy group of CPT-cGMP are essential for facilitating the opening of $\mathrm{ENaC}$ channels by this compound. Serving as an extracellular ligand, CPT-cGMP eliminates sodium self-inhibition, which is a novel mechanism for stimulating salt reabsorption in parallel to the traditional NO/cGMP/PKG signal pathway. In conclusion, ENaC may be a druggable target for CPT-cGMP, leading to treatments for kidney malfunctions in salt reabsorption.
\end{abstract}

Key words: amiloride-sensitive sodium channel; cyclic guanosine nucleotides; molecular docking; lung edema.

\section{Introduction}

Cyclic guanosine monophosphates (cGMP) are important cyclic nucleotides, playing a critical role in signal transduction in many different organisms ${ }^{1}$. Signal transduction in eukaryotic cells is essential for moderating the transmission of information through the cell membrane, and as a second messenger, cGMP regulates numerous essential processes in cells by amplifying external signals, for example, from hormones and neurotransmitters. Cytosolic cGMP binds to cyclic nucleotide-gated ion channels ${ }^{1,2}$ and phosphorylates protein kinase $\mathrm{G}$ (PKG) directly ${ }^{3-5}$.

Amiloride-sensitive epithelial sodium channels (ENaC) behave as ligand-gated channels, similar to several other members of the $\mathrm{ENaC} /$ degenerin fami$1 y^{6}$. In the late part of the renal distal convoluted tubule, sodium is predominately reabsorbed via the electrogenic amiloride-sensitive $\mathrm{ENaC}$. In the connecting tube, and the collecting duct, $\mathrm{ENaC}$ is the only pathway for retaining salt, and $\mathrm{ENaC}$ controls renal sodium excretion and provides the driving force for potassium secretion through the renal outer medullary potassium channel ${ }^{7}$. Loss-of-function $\mathrm{ENaC}$ genetic variants lead to low blood pressure, while gain-of-function mutants have been identified in Liddle's syndrome, which is characterized by increased $\mathrm{ENaC}$ abundance, augmented opening time, and consequent salt retention, and eventually volume-expended hypertension ${ }^{8}$. An autosomal recessive form of pseudohypoaldosteronism type 1 is caused by mutations in $\mathrm{ENaC}$, with usually severe 
and persisting multiorgan symptoms ${ }^{9}$.

Five $\mathrm{ENaC}$ subunits have been cloned to date, namely $\alpha-, \beta-, \gamma_{-}, \delta-$, and $\varepsilon-E N a C$. Among them, the $\beta-$ and $\gamma$-subunits regulate the channel activity of the 'self-conducting' $\alpha-$-, $\delta-$, and $\varepsilon-E N a C$ subunits when heterologously expressed in oocytes and cell lines 10-12. Luminal impermeable reagents and hormones have been confirmed to regulate $\mathrm{ENaC}$ in lung, kidney, and colon, and $\mathrm{ENaC}$ is regulated by a spectrum of protein kinases, such as PKG and protein kinase A (PKA) ${ }^{13-15}$. However, our understanding of the cellular and molecular mechanisms by which cGMP regulates $\mathrm{ENaC}$ is incomplete.

\section{Regulation of Epithelial Sodium Chan- nels by CPT-cGMP}

Cyclic GMP is one of the most prominent nucleotides in eukaryotic cells. Guanylyl cyclases elevate cell cGMP levels, which regulate complex signaling cascades through immediate downstream effectors, cGMP-dependent protein kinases, and cyclic nucleotide-gated ion channels ${ }^{1}$. CPT-cGMP is a derivative analog of parental cGMP, and has long been used for studying the NO/cGMP/PKG cascade $16,17$. Regulation of epithelial sodium channels by CPT-cGMP and its cAMP analog is summarized in Table 1. Species- and culture-dependence of ENaC properties, and the strategies used for elevating cell cGMP content, including nitric oxide (NO) donors and PKG isoform-specific cGMP analogs, may contribute to these divergent observations.

\section{Cyclic GMP/PKGII pathway}

To date, three PKG isoforms have been isolated, namely, PKGI- $\alpha$, PKGI- $\beta$, and PKGII ${ }^{18}$. Accumulating evidence from genetically engineered animals suggests that cardiovascular phenotypes are predominant with the PKGI knockout, while PKGII deficiency leads to dysfunction in epithelial tissues $[19,20]$. Our results using Ussing chamber and voltage clamp techniques showed that 8-pCPT-cGMP increased the amiloride-sensitive short-circuit current across H441 cell monolayers and also increased heterologously expressed $a \beta \gamma \delta-E N a C$ activity in a dose-dependent manner, most probably through the stimulation of PKGII enzymatic activity and subsequent activation of channel function 15 (Figure 1). A carton briefly showed the interaction of cGMP and ENaC (Figure 2). Recent studies showed that PKG-interacting proteins mediate cellular targeting of PKG isoforms by interacting with their leucine zipper domains, and that protein recognition is mediated through surface charge interactions ${ }^{19}$.

\section{Extracellular ligand pathway}

In sharp contrast to the native $\mathrm{ENaC}$, heterologously expressed $a \beta \gamma-E N a C$ in oocytes has been considered to be cAMP/PKA-independent, particularly for acute regulation. The cell-permeable PKGII isoform-specific activator, 8-pCPT-cGMP, acutely stimulates human, rat, and mouse $a \beta \gamma-E N a C$ reversibly. Furthermore, intraoocyte domains of $\mathrm{ENaC}$ subunits and traditional soluble protein kinases may not be targets of this compound ${ }^{20}$. A critical extracellular domain has recently been identified as the 8-CPT-cAMP binding site 21, indicating that 8-CPT-cAMP is an extracellular ligand for ENaC 6, 21. Moreover, 8-CPT-cAMP can stimulate $\delta \beta \gamma-E N a C$ up to approximately 3 -fold, and $\alpha \beta \gamma-\mathrm{ENaC}$ by 2 -fold ${ }^{14}$. Co-expression of $\delta$-ENaC with $\alpha \beta \gamma$ channels conferred CPT-cAMP-mediated activation with an $\mathrm{EC}_{50}$ (concentration for $50 \%$ of maximal effect) value of $30 \mu \mathrm{M}$, similar to that for $\alpha \beta \gamma$ channels $(49 \mu \mathrm{M}){ }^{22}$.

Table 1. Regulation of sodium channel activity by nucleotides.

\begin{tabular}{|c|c|c|c|c|}
\hline Nucleotides & Concentration & Models & Effects & Ref. \\
\hline \multirow[t]{11}{*}{ CPT-cGMP* } & $1 \mu \mathrm{M}$ & Xenopus 2F3 cells & Increase in Isc & 62 \\
\hline & $400 \mu \mathrm{M}$ & Rat ATII cells & No change in Isc & 63 \\
\hline & $2 \mathrm{mM}$ & Rat bronchioalveolar epithelial cells & Increase in Isc/ ${ }^{22} \mathrm{Na}$ influx & 64,65 \\
\hline & $100 \mu \mathrm{M}$ & Rat ATII cells & Increase in whole cell activity & 66 \\
\hline & $4 \mathrm{mM}$ & Human A549 cells & Increase in whole cell activity & 67 \\
\hline & $10 \mu \mathrm{M}$ & Frog urinary bladder epithelium & Increase in single channel activity & 68,69 \\
\hline & $0.1-1000 \mu \mathrm{M}$ & Heterologous human $\alpha \beta \gamma \mathrm{ENaC}$ in oocytes & Increase in whole cell activity & 16 \\
\hline & $0.5 \mathrm{mM}$ & Human lung lobes & Increase in alveolar fluid clearance & 24 \\
\hline & $0.2 \mathrm{mM}$ & Mouse pleural tissues & Increase in Isc & 15 \\
\hline & $1 \mathrm{mM}$ & Rat ATII cells & Decrease in single channel activity & 56 \\
\hline & $100 \mu \mathrm{M}$ & Human A549 cells & Decrease in whole cell activity & 70 \\
\hline \multirow[t]{4}{*}{$\underline{\text { CPT-сAMP }}$} & $100 \mu \mathrm{M}$ & MDCK cells & Increase in Isc & \\
\hline & $40 \mu \mathrm{M}$ & Liddle's disease lymphocytes & Increase in whole cell activity & 71 \\
\hline & $200 \mu \mathrm{M}$ & Heterologous human $\alpha \beta \gamma \mathrm{ENaC}$ in oocytes & Increase in whole cell activity & $14,21,72$ \\
\hline & $100 \mu \mathrm{M}$ & BeWo cells & Increase in whole cell activity & 73 \\
\hline
\end{tabular}

*Abbreviations: ATII, alveolar type II epithelial; MDCK, Madin-Darby canine kidney; Isc, short-circuit current; CPT-cAMP, 8-pCPT-cAMP-Na; CPT-cGMP,

8-pCPT-cGMP-Na. 


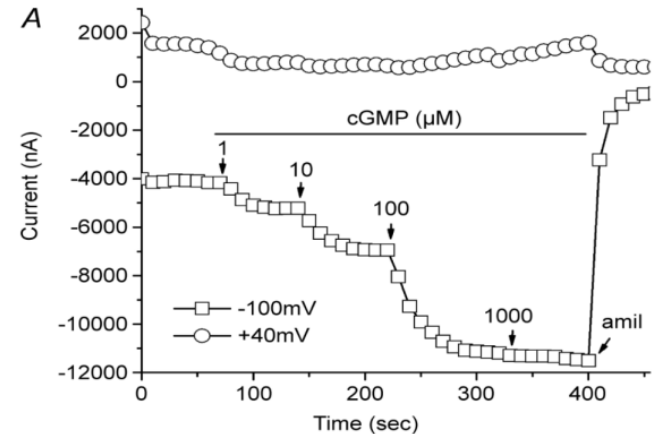

$B$
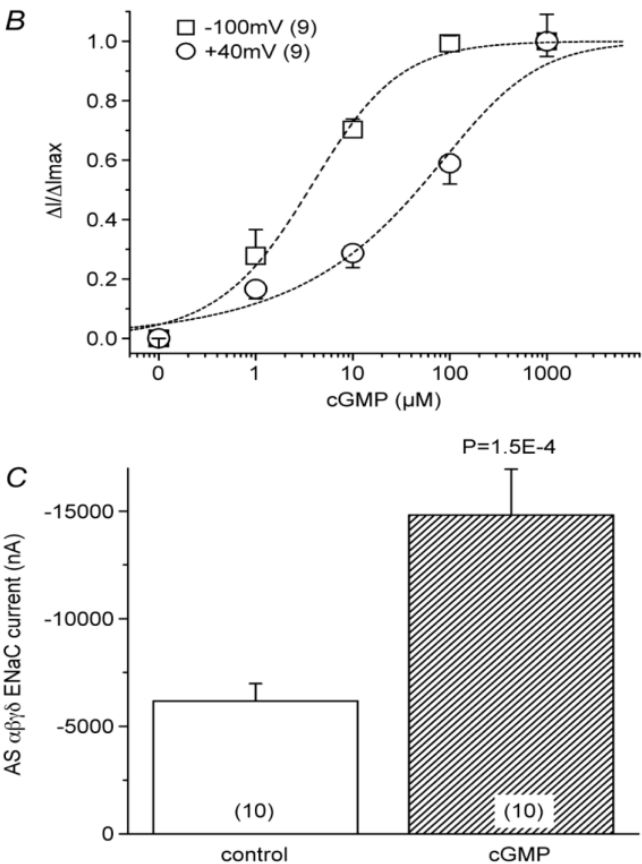

Figure 1. Stimulation of heterologously expressed human ENaCs in Xenopus oocytes by cGMP. A: Representative current trace recorded at $+40 \mathrm{mV}$ and $-100 \mathrm{mV}$. Oocytes were perfused with 8-pCPT-cGMP ranging from $1 \mu \mathrm{M}$ to 1 $\mathrm{mM}$, as indicated by arrows. Amiloride was added to the bath before the recordings were terminated. $\mathrm{B}$ : Dose-response curve. The average cGMP-activated current fraction in the presence of cGMP $(\Delta \mathrm{l})$ was normalized to the maximal cGMP-elevated current $\left(\Delta \mathrm{I}_{\max }\right)$ and plotted as a function of cGMP concentration. Dashed lines and the $\mathrm{EC}_{50}$ value were derived by fitting the raw data with the Hill equation. $n=9$. C: Average amiloride-sensitive (AS) $\alpha \beta \gamma \delta \mathrm{ENaC}$ currents before (control) and after cGMP perfusion. Holding potential, $-100 \mathrm{mV} . \mathrm{n}=10$. Figure reprinted from ${ }^{15}$, and used with permission.

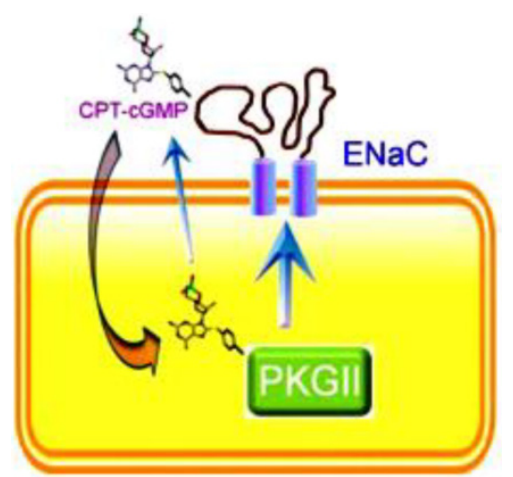

Figure 2. Extracellular and intracellular mechanisms for CPT-cGMP or CPT-cAMP to activate ENaC. These cell permeable compounds, when applied in vivo or in vitro, will stimulates $\mathrm{ENaC}$ activity by both acting as an external ligand to release self-inhibition and as a cytosolic signal molecule to phosphorylate cGKII that subsequently activates $\mathrm{ENaC}$.

\section{Relieving external sodium self-inhibition}

External sodium self-inhibition is an intrinsic feature of ENaC. A rapidly increase in extracellular sodium ions to a physiological concentration $(150 \mathrm{mM}$ for mammals and $100 \mathrm{mM}$ for amphibians) generates a maximal peak current in seconds, and then the permeability of $\mathrm{ENaC}$ to $\mathrm{Na}^{+}$ions is gradually reduced to a relatively stable level with a current level of approximately half of the maximal value. This phenomenon is called extracellular sodium self-inhibition of $\mathrm{ENaC}$ activity. It differs from the down-regulation of $\mathrm{ENaC}$ activity by slowly accumulating intracellular $\mathrm{Na}^{+}$content in a feedback manner. External $\mathrm{Na}^{+}$ self-inhibition is a crucial mechanism to limit overwhelming salt absorption to prevent a quick raise in epithelial cell volume and blood pressure. It maintains salt and fluid homeostasis at the luminal surface of the respiratory system to keep normal cilia beating in the airways, hyperpolarize apical membrane, and finely adjust fluid volume to host leukocytes and physiological regulators as the forefront battle against noxious aspirated insults 22 .

Our previous studies showed that external CPT-CAMP stimulated human, but not rat and murine, $\alpha \beta \gamma-E N a C$ in a dose-dependent and external sodium concentration-dependent fashion ${ }^{14}$. ENaC mutations that abolished self-inhibition ( $\beta \Delta$ V348 and $\gamma \mathrm{H} 233 \mathrm{R})$ almost completely eliminated CPT-cAMP mediated activation. In contrast, mutations that both enhanced self-inhibition and elevated CPT-cAMP sensitivity increased the stimulating effects of the compound. Our above data confirmed that CPT-CAMP acts as a ligand to regulate heterologous $\mathrm{ENaC}$ by relieving self-inhibition. Edelheit et al 23 studied alanine mutations in 17 conserved charged residues of $\mathrm{ENaC}$ and found that these residues are involved in conformational changes that lead to channel constriction and to the sodium self-inhibition response upon sodium ion flooding. Similarly, our recent data showed that elimination of self-inhibition of $a \beta \gamma-E N a C$ may be a novel mechanism for CPT-cGMP to stimulate salt reabsorption in the human epithelium (Figure 3) ${ }^{24}$.

\section{Moiety specificity for CPT-cGMP serving as an $\mathrm{ENaC}$ ligand}

CPT-cGMP, an analog of CPT-cAMP, was capable of activating $\mathrm{ENaC}$ in the identical manner in cell-free outside-out patches ${ }^{16}$. Both point mutations of the putative consensus PKG phosphorylation sites and truncation of entire cytosolic NH2- and $\mathrm{COOH}$-terminal tails of $\mathrm{ENaC}$ did not alter the response to CPT-cGMP. The ENaC activity was activated to the same extent by CPT-cGMP in cells in 
which PKGII expression was knocked down using small interfering RNA. As we demonstrated, the parachlorophenylthio moiety and ribose 2'-hydroxy group of CPT-cGMP are crucial for activating ENaC 16 , and CPT-cGMP may serve as a novel ENaC ligand
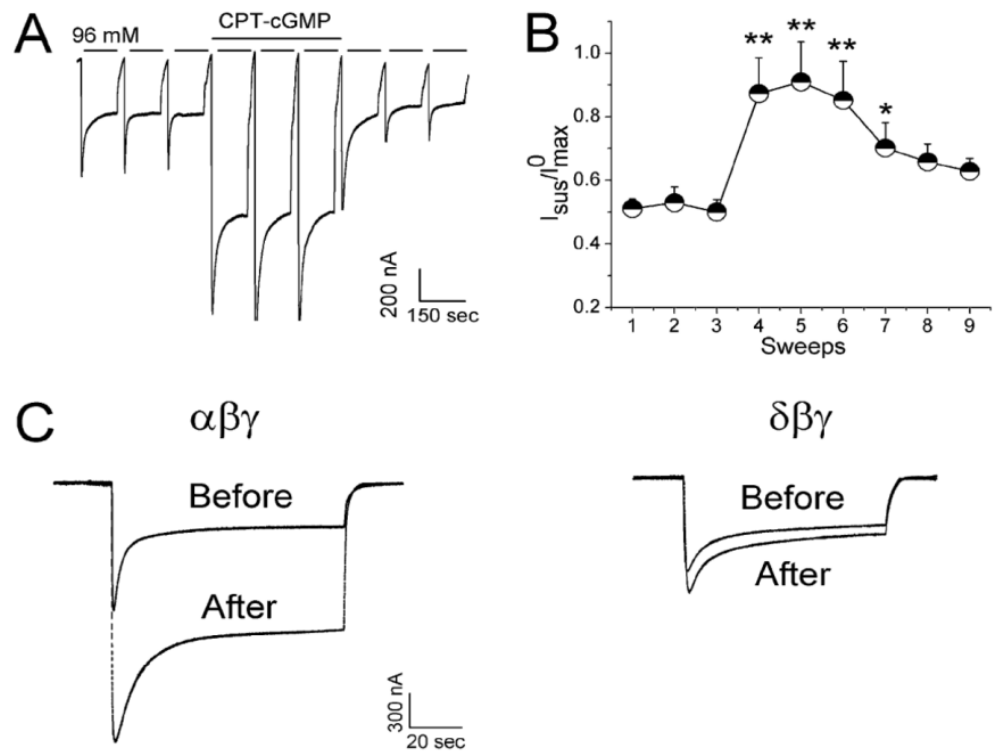

in addition to activating the PKG signal. The strict requirement for both parachlorophenylthio and the ribose 2'-hydroxy groups helps to clarify the basis for the inconsistent results observed with the regulation of $\mathrm{ENaC}$ by a variety of cGMP analogs (Figure 4).

Figure 3. CPT-cGMP modifies self-inhibition of $\alpha \beta Y E N a C$ in oocytes. Self-inhibition was initiated by fast switching the low sodium bath solution ( $1 \mathrm{mM}$ sodium) to regular ND96 medium $(96 \mathrm{mM}$ sodium). A: Whole-cell current trace digitized at $-60 \mathrm{mV}$. CPT-cGMP $(0.2 \mathrm{mM})$ was added after the first three sweeps and washed out for the last three sweeps. B: Normalized and averaged currents; $* \mathrm{P}<0.05$ and $* * \mathrm{P}<0.01$ versus the first sweep. C: Comparison of CPT-cGMP on self-inhibition of $\alpha \beta \gamma$ and $\delta \beta \gamma E N a C$ channels. Paired traces were recorded before and after application of CPT-cGMP, $n=9$. Figure reprinted from ${ }^{24}$, and used with permission.

A
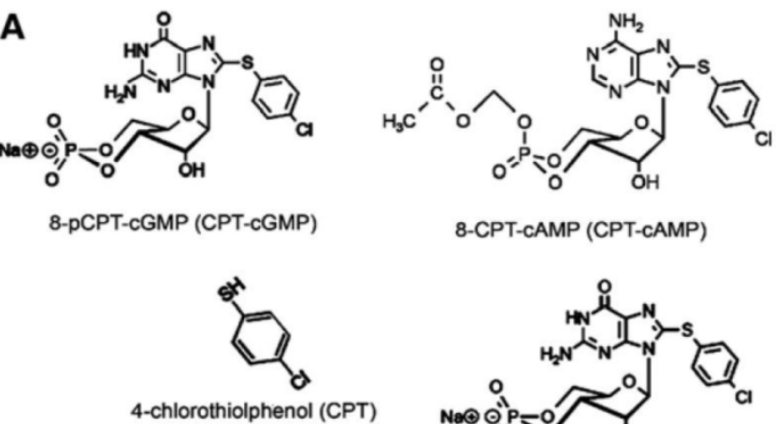

B

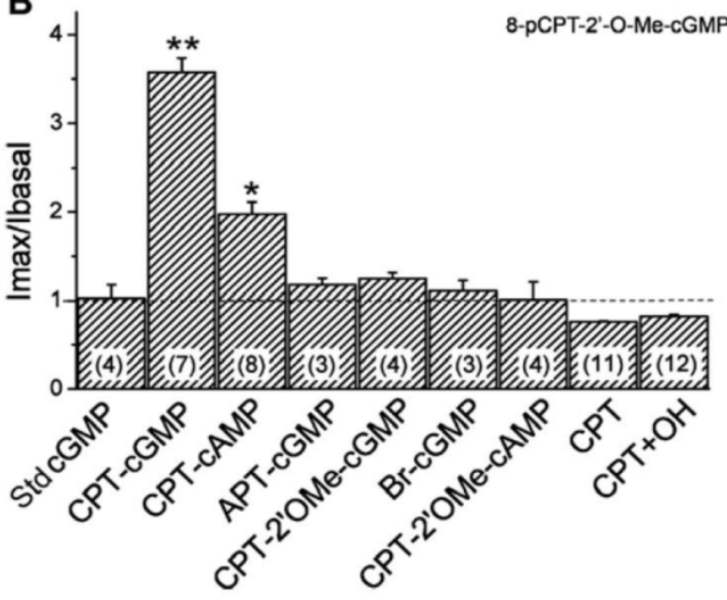

Figure 4. Domain-dependence of CPT-cGMP and CPT-cAMP analogs. A: Modified positions are shown for 8-pCPT-cGMP and 8-CPT-cAMP. B: The responses of human $\alpha \beta Y-E N a C$ to these compounds $(0.2 \mathrm{mM})$ were compared: 8-pCPTcGMP, (CPT-cGMP); 8-CPT-cAMP, (CPT-cAMP); 2-aminophenylthiocGMP, (APT-cGMP); 8-pCPT-methylated ribose 2'-hydroxy (2'-O-Me)-cGMP (CPT-2'OMe-cGMP); Sp-8-Br-cGMP, (Br-cGMP); 8-CPT-2'-O-Me-cAMP, (CPT-2'OMe-cAMP), 4-chlorothiolphenol, (CPT); a mixture of CPT and $\mathrm{KOH}$, $(\mathrm{CPT}+\mathrm{OH})$. The normalized currents before and after application of these compounds were compared with that of the standard cGMP molecule (Std cGMP). $* * P<0.01, * P<0.05$. Numbers in parentheses are the number of oocytes examined for each group. Figure reprinted from ${ }^{16}$, and used with permission.

\section{CPT-cGMP ligand docking to ENaC}

In our previous experiment, we constructed mutants abolishing ( $\beta$ V348 and $\gamma \mathrm{H} 233 \mathrm{R})$, or augmenting (aY458A and $\gamma \mathrm{M} 432 \mathrm{G}), \mathrm{ENaC}$ self-inhibition 14,24 . The mutations eliminating self-inhibition resulted in a loss of response to CPT-cGMP, whereas those enhancing self-inhibition facilitated the stimulatory effects of this compound. Figure 5 shows the potential binding sites for the CPT-cGMP ligand in ENaC domains that are crucial for self-inhibition. $\beta \mathrm{V} 348$ is located in the center of the palm region of the subunit, and $\gamma \mathrm{H} 233$ is located in the vicinity of the putative binding site for protons. These domains potentially directly or allosterically interact with CPT-cGMP. 


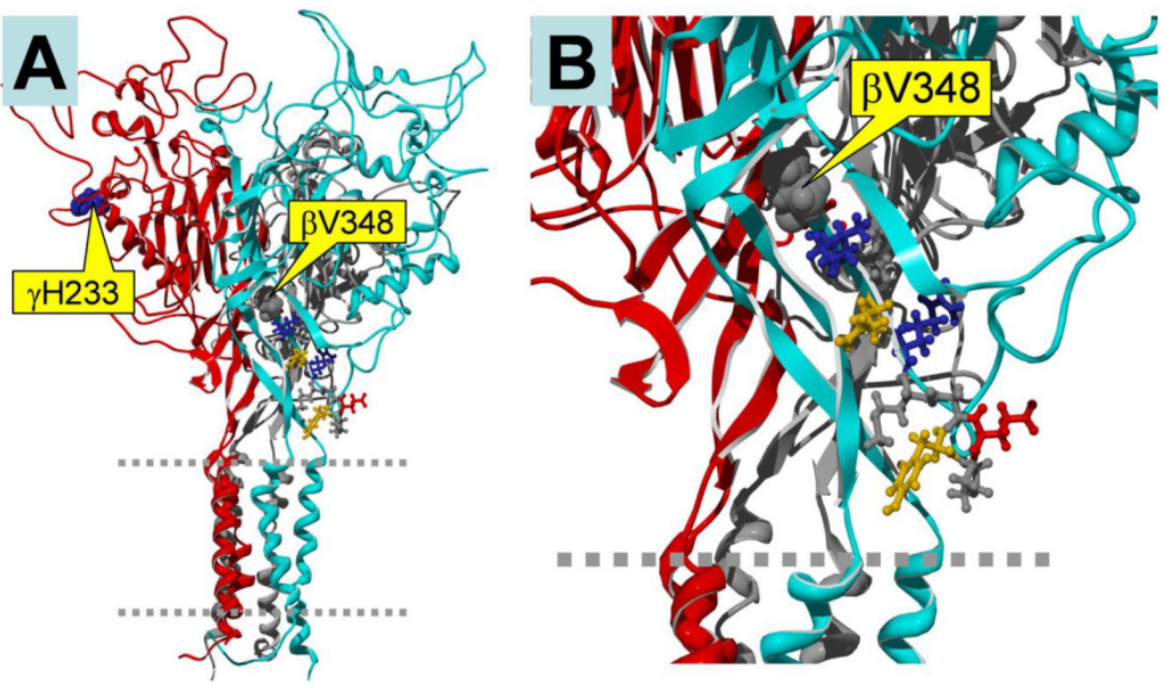

Figure 5. Homology model of trimeric human $\alpha \beta \gamma \mathrm{ENaC}$. The subunits are color-coded as follows: $\alpha$, grey (back, center); $\beta$, cyan (front, right); $\gamma$, red (front, left). A: Side view of the entire trimer. Two dashed grey lines indicate the plasma membrane. The locations of the mutations $\gamma \mathrm{H} 233$ and $\beta \mathrm{V} 348$ are marked by yellow boxes. $\mathrm{B}$ : Close-up view, showing the location of $\beta$ V348. Note that $\beta V 348$ is located in the center of the palm region of the subunit, and its downstream residues extend to the wrist region of the subunit that seems to be important in the coupling between extracellular domains to the pore region. Thus, deletion of $\beta \mathrm{V} 348$ may change the position and orientation of the downstream residues. $\gamma \mathrm{H} 233$ is located in the vicinity of the putative binding site for protons. Since 8-CPT-cGMP is much larger than a proton, its binding site may include the $\mathrm{H} 233$ residue.

\section{Specific domains/sites changing self-inhibition}

His(88) and Asp(516) of the $\gamma$ subunit play a role in the $\mathrm{Zn}^{2+}$-regulating sodium self-inhibition mentioned above. Recent studies showed that palmitoylation of the $\gamma$ subunit activates $\mathrm{ENaC}$ by increasing the open probability of the channels ${ }^{40}$. ENaC mutants with the mutations $\gamma \mathrm{C} 33 \mathrm{~A}, \gamma \mathrm{C} 41 \mathrm{~A}$, or $\gamma C 33 \mathrm{~A} / \mathrm{C} 41 \mathrm{~A}$ have significantly enhanced sodium self-inhibition and reduced open probability compared with wild type $\mathrm{ENaCs}$, suggesting that ENaC palmitoylation is an important post-translational mechanism of channel regulation. Exon 11 within the human $\alpha, \beta$, and $\gamma$ $\mathrm{ENaC}$ genes encodes structurally homologous yet functionally diverse domains,

\section{Self-Inhibition as a Therapeutic Mecha- nism}

\section{Reagents able to release self-inhibition}

Previous results suggested that external $\mathrm{Zn}^{2+}$ rapidly and reversibly activates $\mathrm{ENaC}$ in a dose-dependent manner by relieving the channel from sodium self-inhibition ${ }^{25}$. In addition to $\mathrm{Zn}$, extracellular chloride 26 , temperature ${ }^{27,28}$, halogenated gases $27-29$, sulfhydryl group-modifying reagents (e.g., p-chloromercuriphenylsulfonate, pCMPS and p-chloromercuribenzoate, pCMB) 30, p-chloromercuribenzoate benzimidazolylguanidine ${ }^{30-33}$, protons 26 , cupper ${ }^{34}$, and proteases $28,35,36$ are also proposed to modulate ENaC-gating by relieving sodium self-inhibition. A classic earlier review summarized most of these reagents $27,37,38$. Non-cleaved channels have a low intrinsic open probability that may reflect enhanced channel inhibition by external sodium, and cleavage at a minimum of two sites within the a- or $\mathrm{\gamma}$-ENaC subunits is required to activate the channel, presumably by releasing inhibitory fragments ${ }^{39}$. The extent of $\mathrm{ENaC}$ proteolysis is dependent on channel residency time at the plasma membrane, as well as on the balance between levels of expression of proteases that activate epithelial sodium channels and inhibitors of these proteases. For example, furin cleavage of ENaC subunits activates the channels by relieving sodium self-inhibition, and this activation requires that the a-ENaC subunit be cleaved twice ${ }^{35}$. and exon 11 in the a-subunit encodes a module that regulates channel gating ${ }^{41}$.

In contrast to the other mutations, $\gamma \mathrm{L} 511 \mathrm{Q}$ largely eliminated the sodium self-inhibition response, reflecting a down-regulation of $\mathrm{ENaC}$ open probability by extracellular sodium ${ }^{42}$. $\gamma \mathrm{L} 511 \mathrm{Q}$ is a gain-of-function human $\mathrm{ENaC}$ variant and it enhances $\mathrm{ENaC}$ activity by increasing channel open probability and dampens channel regulation by extracellular sodium and proteases ${ }^{42}$.

\section{Therapeutic effects of targeting self-inhibition}

Renal handling of sodium and water is abnormal in chronic kidney diseases. Filtrated sodium is reabsorbed from the glomerular filtrate, and potassium is secreted through a tight epithelium in the kidney. Sodium crosses the apical membrane and enters the epithelial cell through the ion-selective $\mathrm{ENaC}^{43}$. $\mathrm{ENaC}$ is responsible for the reabsorption of sodium through the apical membrane of the connecting tubule and the collecting duct, and plays a key role in controlling sodium balance, extracellular fluid volume, and blood pressure ${ }^{44}$. Regulated epithelial sodium channel proteolysis has been observed in rat kidney and in human airway epithelia. Pseudohypoaldosteronism type 1 is a monogenic disorder of mineralocorticoid resistance characterized by salt-wasting, hyperkalemia, high aldosterone levels, and failure to thrive ${ }^{45}$. An autosomal recessive form of pseudohypoaldosteronism type 1 is caused by mutations in $\mathrm{ENaC}$, and is usually associated with 
severe and persisting multiorgan symptoms. The relief of self-inhibition by CPT-cAMP contributes to the acute effects, in addition to the well-known cAMP-PKA signal pathway ${ }^{14}$. In fact, the clinical relevance of the abnormal regulation of $\mathrm{ENaC}$ by CPT-cAMP has been implicated in the upregulation of $\mathrm{ENaC}$ in autosomal recessive pseudohypoaldosteronism type $1^{46}$.

Another distressed transapical sodium transport occurs in injured lungs, for example, acute lung injury (ALI) and acute respiratory distress syndrome (ARDS) (please see classical reviewes 47-51). Apical $\mathrm{ENaC}$ contributes to up to $60 \%$ of transepithelial sodium transport in mammalian lungs under physiological conditions. This critical process is sensitive to aspirated pollutants, allergens, pathogens, and bacterial endotoxins. In addition to increased leaking through alveolar microvascular endothelium (indirect ALI), lung edema ususally results from reduced edema fluid resolution via $\mathrm{ENaC}$ (direct $\mathrm{ALI}$ ). $\mathrm{ENaC}$ is a promising target for developing new therapeutical strategies to alleviate lung edema, at least for the phenotype of direct ALI 52,53 .

\section{CPT-cGMP and self-inhibition}

Human serum cGMP level is $6 \mathrm{nM}$ and 3-time greater in human bronchoalveolar lavage ${ }^{54}$. It appears that cGMP may serve as an autocrine and paracrine to regulate $\mathrm{ENaC}$ function. However, the effective dose for CPT-cGMP and CPT-cAMP to blunt self-inhibition is micromolar, suggesting an uncertain physiological role for cGMP and analogs. A large dose of cGMP compound $(1 \mathrm{mg} / \mathrm{kg})$ was administered to patients as reported by two clinical trials 55 , and numerous preclinical studies (from $100 \mu \mathrm{M}$ to $2 \mathrm{mM}$ ) $56-58$. It is therefore feasible to apply aerosolized nucleotides to mitigate edematous lung injury. We have demonstrated that CPT-cGMP up-regulates $\mathrm{ENaC}$ via two mechanisms: release self-inhibition externally and activates ENaC through cGMP/cGKII pathway intracellularly ${ }^{24}$. Thus, these compounds could regulate sodium absorption via either or both mechanisms in a cell permeability-dependent manner. Administration of cAMP could be a potent pharmaceutical treatment for edematous lung injury 59, and cGMP may have similar potential. cGMP increased in murine and rat lungs both in vivo and in vitro following $\mathrm{NO}$ application ${ }^{60}$, and increased cGMP may augment the cGMP-sensitive pathway for lung fluid removal from alveolar sacs ${ }^{61}$. Our previous study demonstrated for the first time that PKGII is an ENaC activator in non-ciliated bronchial secretory cells ${ }^{15}$. Accordingly, upregulation of the rate-limiting ENaCs in respiratory epithelial cells by specific PKGII activators may be a potent clinicopharmaceutical strategy for alleviating airspace flooding in fatal edematous lung diseases. The observation of our previous study that specific moieties of 8-pCPT-cGMP are required for activating $\mathrm{ENaC}$ may provide pivotal information for developing potential ENaC channel openers structurally related to 8-pCPT-cGMP, which would be extremely useful for treating diseases associated with lower $\mathrm{ENaC}$ function. We postulate that when the tight epithelial layer is damaged, for example, in injured lungs, even though the mixture of extracellular matrix proteins, including collagens, albumin, and fibrins, will seal the epithelial cell-free alveolar surface, the potency of $\mathrm{ENaC}$ stimulator will be limited significantly. Therefore, the integrity of the tight alveolar epithelium should be a key factor to be considered for the usage of $\mathrm{ENaC}$ agonists. The anticipated restore of alveolar fluid clearance may be seen at the earlier stage of ALI and lung edema mainly caused by injured pulmonary vasculature or post regeneration of alveolar epithelium by stem cells/progenitors.

\section{Conclusions and Perspectives}

$\mathrm{ENaC}$ is involved in edema formation and kidney disorders. cGMP, either by serving as a ligand to regulate cyclic nucleotide-gated ion channels or by acting upstream of the PKG signaling systems, has a role in the elimination of $\mathrm{ENaC}$ self-inhibition, suggesting a novel mechanism for CPT-cGMP to stimulate salt reabsorption. Compounds such as specific PKGII activators and/or self-inhibition inhibitors could be the basis for novel pharmaceutical interventions for combating diseases associated with impaired $\mathrm{ENaC}$ function. Future directions for study include optimizing cGMP structure to potentiate its efficacy in activating $\mathrm{ENaC}$, evaluating its pharmaceutical relevance in preclinical and clinical models with impaired $\mathrm{ENaC}$ activity, and confirming the binding sites of cGMP in ENaC.

\section{Acknowledgements}

The authors are grateful for helpful discussions with Dr. Run-Zhen Zhao (University of Texas Health Science Center at Tyler), and Dr. Zai-Xing Chen (China Medical University). This work was partially supported by NIH grants HL87017 and HL095435, the American Heart Association (AHA 14GRNT20130034 to HLJ), and the National Science Foundation of China (grants 81270098 to HGN, 31270967 and 31571407 to QL).

\section{Abbreviations}

cAMP: cyclic adenosine monophosphate; cGMP: cyclic guanosine monophosphate; $\mathrm{EC}_{50}$ : concentration for $50 \%$ of maximal effect; $\mathrm{ENaC}$ : epithelial sodium 
channel; PKA: protein kinase A; PKG: protein kinase G; NO: nitric oxide

\section{Competing Interests}

The authors declare no conflicts of interest.

\section{References}

1. Lucas KA, Pitari GM, Kazerounian S, Ruiz-Stewart I, Park J, Schulz S, et al. Guanylyl cyclases and signaling by cyclic GMP. Pharmacol Rev. 2000; 52:375-414.

2. Kaupp UB, Seifert R. Cyclic nucleotide-gated ion channels. Physiol Rev. 2002; 82:769-824.

3. Gudi T, Huvar I, Meinecke M, Lohmann SM, Boss GR, Pilz RB. Regulation of gene expression by cGMP-dependent protein kinase. Transactivation of the c-fos promoter. J Biol Chem. 1996; 271:4597-600.

4. Edwards AS, Scott JD. A-kinase anchoring proteins: protein kinase A and beyond. Curr Opin Cell Biol. 2000; 12:217-21.

5. Kim E, Park JM. Identification of novel target proteins of cyclic GMP signaling pathways using chemical proteomics. J Biochem Mol Biol. 2003; 36:299-304.

6. Horisberger JD, Chraibi A. Epithelial sodium channel: a ligand-gated channel? Nephron Physiol. 2004; 96:37-41.

7. Ronzaud C, Staub O. Ubiquitylation and control of renal $\mathrm{Na}+$ balance and blood pressure. Physiology (Bethesda). 2014; 29:16-26.

8. Svenningsen P, Andersen H, Nielsen LH, Jensen BL. Urinary serine proteases and activation of $\mathrm{ENaC}$ in kidney--implications for physiological renal salt handling and hypertensive disorders with albuminuria. Pflugers Arch. 2015; 467:531-42.

9. Zennaro MC, Hubert EL, Fernandes-Rosa FL. Aldosterone resistance: structural and functional considerations and new perspectives. Mol Cell Endocrinol. 2012; 350:206-15.

10. Ji HL, Su XF, Kedar S, Li J, Barbry P, Smith PR, et al. Delta-subunit confers novel biophysical features to alpha beta gamma-human epithelial sodium channel (ENaC) via a physical interaction. J Biol Chem. 2006; 281:8233-41.

11. Zhao RZ, Nie HG, Su XF, Han DY, Lee A, Huang Y, et al. Characterization of a novel splice variant of delta ENaC subunit in human lungs. Am J Physiol Lung Cell Mol Physiol. 2012; 302:L1262-72.

12. Canessa CM, Horisberger JD, Rossier BC. Epithelial sodium channel related to proteins involved in neurodegeneration. Nature. 1993; 361:467-70.

13. Ji HL, Song W, Gao Z, Su XF, Nie HG, Jiang Y, et al. SARS-CoV proteins decrease levels and activity of human ENaC via activation of distinct PKC isoforms. Am J Physiol Lung Cell Mol Physiol. 2009; 296:L372-83.

14. Molina R, Han DY, Su XF, Zhao RZ, Zhao M, Sharp GM, et al. Cpt-cAMP activates human epithelial sodium channels via relieving self-inhibition. Biochim Biophys Acta. 2011; 1808:1818-26.

15. Nie HG, Chen L, Han DY, Li J, Song WF, Wei SP, et al. Regulation of epithelial sodium channels by cGMP/PKGII. J Physiol. 2009; 587:2663-76.

16. Nie HG, Zhang W, Han DY, Li QN, Li J, Zhao RZ, et al. 8-pCPT-cGMP stimulates alphabetagamma-ENaC activity in oocytes as an external ligand requiring specific nucleotide moieties. Am J Physiol Renal Physiol. 2010; 298: F323-34.

17. Broderick KE, Zhang T, Rangaswami H, Zeng Y, Zhao X, Boss GR, et al Guanosine 3',5'-cyclic monophosphate (cGMP)/cGMP-dependent protein kinase induce interleukin-6 transcription in osteoblasts. Mol Endocrinol. 2007; $21 \cdot 1148-62$

18. Schlossmann J, Feil R, Hofmann F. Signaling through NO and cGMP-dependent protein kinases. Ann Med. 2003; 35:21-7.

19. Reger AS, Yang MP, Koide-Yoshida S, Guo E, Mehta S, Yuasa K, et al. Crystal structure of the cGMP-dependent protein kinase II leucine zipper and Rab11b protein complex reveals molecular details of G-kinase-specific interactions. J Biol Chem. 2014; 289:25393-403.

20. Nie HG, Zhang W, Han DY, Li ON, Li J, Zhao RZ, et al. 8-pCPT-cGMP stimulates alphabetagamma-ENaC activity in oocytes as an external ligand requiring specific nucleotide moieties. Am J Physiol Renal Physiol. 2010; 298:F323-34.

21. Renauld S, Allache R, Chraibi C. Ile481 from the guinea pig alpha-subunit plays a major role in the activation of ENaC by cpt-cAMP. Cell Physiol Biochem. 2008; 22:101-8.

22. Ji HL, Zhao RZ, Chen ZX, Shetty S, Idell S, Matalon S, delta ENaC: a novel divergent amiloride-inhibitable sodium channel. Am J Physiol Lung Cell Mol Physiol. 2012; 303:L1013-26.

23. Edelheit O, Ben-Shahar R, Dascal N, Hanukoglu A, Hanukoglu I. Conserved charged residues at the surface and interface of epithelial sodium channel subunits--roles in cell surface expression and the sodium self-inhibition response. FEBS J. 2014; 281:2097-111.

24. Han DY, Nie HG, Su XF, Shi XM, Bhattarai $D$, Zhao $M$, et al. 8-(4-chlorophenylthio)-guanosine-3',5'-cyclic monophosphate-Na stimulates human alveolar fluid clearance by releasing external $\mathrm{Na}+$ self-inhibition of epithelial Na+ channels. Am J Respir Cell Mol Biol. 2011; 45:1007-14.

25. Sheng S, Bruns JB, Kleyman TR. Extracellular histidine residues crucial for $\mathrm{Na}+$ self-inhibition of epithelial Na+ channels. J Biol Chem. 2004; 279:9743-9.
26. Collier DM, Snyder PM. Extracellular chloride regulates the epithelial sodium channel. J Biol Chem. 2009; 284:29320-5.

27. Chraibi A, Horisberger JD. Na self inhibition of human epithelial Na channel: temperature dependence and effect of extracellular proteases. J Gen Physiol. 2002; 120:133-45.

28. Chraibi A, Horisberger JD. Dual effect of temperature on the human epithelial $\mathrm{Na}+$ channel. Pflugers Arch. 2003; 447:316-20.

29. Roch A, Shlyonsky V, Goolaerts A, Mies F, Sariban-Sohraby S. Halothane directly modifies $\mathrm{Na}+$ and $\mathrm{K}+$ channel activities in cultured human alveolar epithelial cells. Mol Pharmacol. 2006; 69:1755-62.

30. Luger A, Turnheim K. Modification of cation permeability of rabbit descending colon by sulphydryl reagents. J Physiol. 1981; 317:49-66

31. Friis S, Nielsen R. Effect of the putative Ca2+-receptor agonist Gd3+ on the active transepithelial Na+ transport in frog skin. J Membr Biol. 2001; 184:291-7.

32. $\mathrm{Li} \mathrm{JH}$, Lindemann B. Chemical stimulation of $\mathrm{Na}$ transport through amiloride-blockable channels of frog skin epithelium. J Membr Biol. 1983; 75:179-92.

33. Zeiske $\mathrm{W}$, Lindemann B. Chemical stimulation of $\mathrm{Na}+$ current through the outer surface of frog skin epithelium. Biochim Biophys Acta. 1974; 352:323-6.

34. Ferreira KT, Guerreiro MM, Svensson WM. The mechanism of action of Cu2+ on the frog skin. Biochim Biophys Acta. 1979; 552:341-5.

35. Sheng S, Carattino MD, Bruns JB, Hughey RP, Kleyman TR. Furin cleavage activates the epithelial $\mathrm{Na}+$ channel by relieving $\mathrm{Na}+$ self-inhibition. Am J Physiol Renal Physiol. 2006; 290:F1488-96.

36. Molina R, Han DY, Su XF, Zhao RZ, Zhao M, Sharp GM, et al. Cpt-cAMP activates human epithelial sodium channels via relieving self-inhibition. Biochim Biophys Acta. 2011; 1808:1818-26.

37. Garty H, Benos DJ. Characteristics and regulatory mechanisms of the amiloride-blockable Na+ channel. Physiol Rev. 1988; 68:309-73.

38. Collier DM, Snyder PM. Extracellular protons regulate human ENaC by modulating Na+ self-inhibition. J Biol Chem. 2009; 284:792-8.

39. Hughey RP, Carattino MD, Kleyman TR. Role of proteolysis in the activation of epithelial sodium channels. Curr Opin Nephrol Hypertens. 2007; 16:444-50.

40. Mukherjee A, Mueller GM, Kinlough CL, Sheng N, Wang Z, Mustafa SA, et al. Cysteine palmitoylation of the gamma subunit has a dominant role in modulating activity of the epithelial sodium channel. J Biol Chem. 2014; 289:14351-9.

41. Chen Z, Zhao R, Zhao M, Liang X, Bhattarai D, Dhiman R, et al. Regulation of epithelial sodium channels in urokinase plasminogen activator deficiency. Am J Physiol Lung Cell Mol Physiol. 2014; 307:L609-17.

42. Chen J, Kleyman TR, Sheng S. Gain-of-function variant of the human epithelial sodium channel. Am J Physiol Renal Physiol. 2013; 304:F207-13.

43. Wang $Y B$, Leroy $V$, Maunsbach AB, Doucet A, Hasler U, Dizin E, et al. Sodium transport is modulated by p38 kinase-dependent cross-talk between ENaC and Na,K-ATPase in collecting duct principal cells. J Am Soc Nephrol. 2014; 25:250-9.

44. Graffe CC, Bech JN, Lauridsen TG, Pedersen EB. Urinary excretion of AQP2 and $\mathrm{ENaC}$ in autosomal dominant polycystic kidney disease during basal conditions and after a hypertonic saline infusion. Am J Physiol Renal Physiol. 2014; 302:F917-27.

45. Dirlewanger M, Huser D, Zennaro MC, Girardin E, Schild L, Schwitzgebel VM. A homozygous missense mutation in SCNN1A is responsible for a transient neonatal form of pseudohypoaldosteronism type 1. Am J Physiol Endocrinol Metab. 2011; 301:E467-73.

46. Bubien JK, Ismailov II, Berdiev BK, Cornwell T, Lifton RP, Fuller CM, et al. Liddle's disease: abnormal regulation of amiloride-sensitive $\mathrm{Na}+$ channels by beta-subunit mutation. Am J Physiol. 1996; 270:C208-13.

47. Matthay MA, Folkesson HG, Clerici C. Lung epithelial fluid transport and the resolution of pulmonary edema. Physiol Rev. 2002; 82:569-600.

48. Berthiaume $Y$, Matthay MA. Alveolar edema fluid clearance and acute lung injury. Respir Physiol Neurobiol. 2007; 159:350-9.

49. Matalon S, Lazrak A, Jain L, Eaton DC. Invited review: biophysical properties of sodium channels in lung alveolar epithelial cells. J Appl Physiol. 2002; 93:1852-9.

50. Eaton DC, Helms MN, Koval M, Bao HF, Jain L. The contribution of epithelial sodium channels to alveolar function in health and disease. Annu Rev Physiol. 2009; 71:403-23.

51. Matalon S, Bartoszewski R, Collawn JF. Role of Epithelial Sodium Channels $(\mathrm{ENaC})$ In the Regulation of Lung Fluid Homeostasis. Am J Physiol Lung Cell Mol Physiol. 2015:ajplung 0031902015.

52. Czikora I, Alli A, Bao HF, Kaftan D, Sridhar S, Apell HJ. A novel tumor necrosis factor-mediated mechanism of direct epithelial sodium channel activation. Am J Respir Crit Care Med. 2014; 190:522-32.

53. Giraldez T, Dominguez J, Alvarez de la Rosa D. ENaC in the brain--future perspectives and pharmacological implications. Curr Mol Pharmacol. 2013; 6:44-9.

54. Arias-Diaz J, Vara E, Torres-Melero J, Garcia C, Baki W, Ramirez-Armengol JA, Role of Epithelial Sodium Channels (ENaC) In the Regulation of Lung Fluid Homeostasis. Nitrite/nitrate and cytokine levels in bronchoalveolar lavage fluid of lung cancer patients. Cancer. 1994; 74:1546-51.

55. Sandera P, Hillinger S, Stammberger U, Schoedon G, Zalunardo M, Weder W, Role of Epithelial Sodium Channels (ENaC) In the Regulation of Lung Fluid Homeostasis. 8-Br-cyclic GMP given during reperfusion improves post-transplant lung edema and free radical injury. J Heart Lung Transplant. 2000; $19: 173-8$ 
56. Jain L, Chen XJ, Brown LA, Eaton DC. Nitric oxide inhibits lung sodium transport through a cGMP-mediated inhibition of epithelial cation channels. Am J Physiol. 1998; 274:L475-84.

57. Chen L, Bosworth CA, Pico T, Collawn JF, Varga K, Gao Z, et al. DETANO and nitrated lipids increase chloride secretion across lung airway cells. Am J Respir Cell Mol Biol. 2008; 39:150-62.

58. Kemp PJ, Kim KJ, Borok Z, Crandall ED. Re-evaluating the $\mathrm{Na}^{+}$conductance of adult rat alveolar type II pneumocytes: evidence for the involvement of cGMP-activated cation channels. J Physiol. 2001; 536:693-701.

59. Chen L, Song W, Davis IC, Shrestha K, Schwiebert E, Sullender WM, et al. Inhibition of $\mathrm{Na}+$ transport in lung epithelial cells by respiratory syncytial virus infection. Am J Respir Cell Mol Biol. 2009; 40:588-600.

60. Hardiman KM, McNicholas-Bevensee CM, Fortenberry J, Myles CT, Malik B, Eaton $\mathrm{DC}$, et al. Regulation of amiloride-sensitive $\mathrm{Na}(+)$ transport by basal nitric oxide. Am J Respir Cell Mol Biol. 2004; 30:720-8.

61. Sakuma T, Zhao Y, Sugita M, Sagawa M, Toga H, Ishibashi T, et al. Malnutrition impairs alveolar fluid clearance in rat lungs. Am J Physiol Lung Cell Mol Physiol. 2004; 286:L1268-74

62. Guo LJ, Alli AA, Eaton DC, Bao HF. ENaC is regulated by natriuretic peptide receptor-dependent cGMP signaling. Am J Physiol Renal Physiol. 2013; 304:F930-7.

63. Guo Y, DuVall MD, Crow JP, Matalon S. Nitric oxide inhibits Na+ absorption across cultured alveolar type II monolayers. Am J Physiol. 1998; 274:L369-77.

64. Rafii B, Gillie DI, Sulowski C, Hannam V, Cheung T, Otulakowski G, et al. Pulmonary oedema fluid induces non-alpha-ENaC-dependent $\mathrm{Na}(+)$ transport and fluid absorption in the distal lung. J Physiol. 2002; 544:537-48.

65. Schwiebert EM, Potter ED, Hwang TH, Woo JS, Ding C, Qiu W, et al. cGMP stimulates sodium and chloride currents in rat tracheal airway epithelia. Am J Physiol. 1997; 272:C911-22.

66. Kemp PJ, Kim KJ, Borok Z, Crandall ED. Re-evaluating the $\mathrm{Na}(+)$ conductance of adult rat alveolar type II pneumocytes: evidence for the involvement of cGMP-activated cation channels. J Physiol. 2001; 536:693-701.

67. Xu W, Leung S, Wright J, Guggino SE. Expression of cyclic nucleotide-gated cation channels in airway epithelial cells. J Membr Biol. 1999; 171:117-26.

68. Yamada T, Konno N, Matsuda K, Uchiyama M. Frog atrial natriuretic peptide and cGMP activate amiloride-sensitive $\mathrm{Na}(+)$ channels in urinary bladder cells of Japanese tree frog, Hyla japonica. J Comp Physiol B. 2007; 177:503-8.

69. Yamada T, Matsuda K, Uchiyama M. Frog ANP increases the amiloride-sensitive $\mathrm{Na}(+)$ channel activity in urinary bladder cells of Japanese tree frog, Hyla japonica. Gen Comp Endocrinol. 2007; 152:286-8.

70. Lazrak A, Nielsen VG, Matalon S. Mechanisms of increased $\mathrm{Na}(+)$ transport in ATII cells by cAMP: we agree to disagree and do more experiments. Am J Physiol Lung Cell Mol Physiol. 2000; 278:L233-8.

71. Bubien JK, Watson B, Khan MA, Langloh AL, Fuller CM, Berdiev B, et al. Expression and regulation of normal and polymorphic epithelial sodium channel by human lymphocytes. J Biol Chem. 2001; 276:8557-66.

72. Robins GG, MacLennan KA, Boot-Handford RP, Sandle GI. Rapid stimulation of human renal ENaC by cAMP in Xenopus laevis oocytes. J Physiol Biochem. 2013; 69:419-27.

73. del Monaco S, Assef Y, Kotsias BA. Epithelial sodium channel in a human trophoblast cell line (BeWo). J Membr Biol. 2008; 223:127-39. 